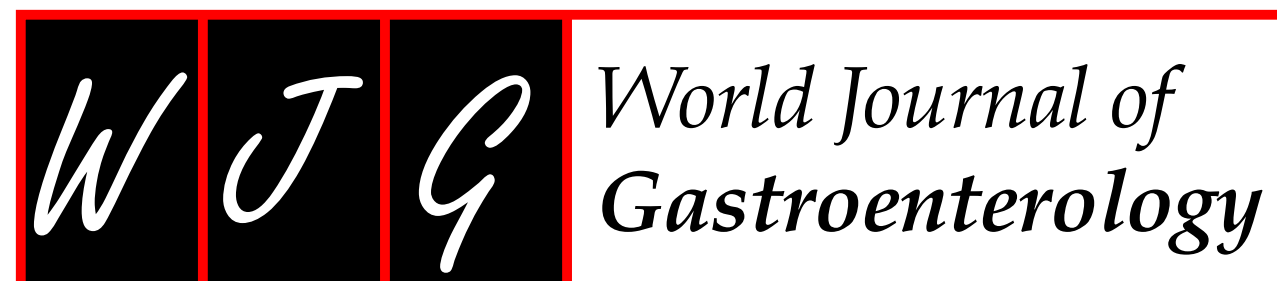

Submit a Manuscript: http:/ / www.wjgnet.com/esps/

Help Desk: http:/ /www.wjgnet.com/esps/helpdesk.aspx

DOI: $10.3748 /$ wjg.v21.i38.10866

World J Gastroenterol 2015 October 14; 21(38): 10866-10873

ISSN 1007-9327 (print) ISSN 2219-2840 (online)

(C) 2015 Baishideng Publishing Group Inc. All rights reserved.

ORIGINAL ARTICLE

Retrospective Cohort Study

\title{
Clinical characteristics of hepatoduodenal lymph node metastasis in gastric cancer
}

Taisuke Imamura, Shuhei Komatsu, Daisuke Ichikawa, Toshiyuki Kosuga, Kazuma Okamoto, Hirotaka Konishi, Atsushi Shiozaki, Hitoshi Fujiwara, Eigo Otsuji

Taisuke Imamura, Shuhei Komatsu, Daisuke Ichikawa, Toshiyuki Kosuga, Kazuma Okamoto, Hirotaka Konishi, Atsushi Shiozaki, Hitoshi Fujiwara, Eigo Otsuji, Division of Digestive Surgery, Department of Surgery, Kyoto Prefectural University of Medicine, Kyoto 602-8566, Japan

Author contributions: Imamura $\mathrm{T}$ and Komatsu S contributed equally to this work; Imamura T, Komatsu S, Ichikawa D and Otsuji E designed the research; Imamura T, Kosuga T, Okamoto $\mathrm{K}$ and Shiozaki A performed the research; Imamura T, Konishi $\mathrm{H}$ and Fujiwara $\mathrm{H}$ analyzed the data; Imamura $\mathrm{T}$ and Komatsu $\mathrm{S}$ wrote the paper.

Institutional review board statement: This study was institutionally reviewed and comprehensively approved by the Kyoto Prefectural University of Medicine.

Informed consent statement: The patients provided informed written consent prior to study enrollment.

Conflict-of-interest statement: The authors have no conflict of interest to declare.

Data sharing statement: Technical appendix and study data are available from the corresponding author at skomatsu@koto. kpu-m.ac.jp (Shuhei Komatsu) under the permission of Shuhei Komatsu. Participants gave informed consent for data sharing. No additional data are available.

Open-Access: This article is an open-access article which was selected by an in-house editor and fully peer-reviewed by external reviewers. It is distributed in accordance with the Creative Commons Attribution Non Commercial (CC BY-NC 4.0) license, which permits others to distribute, remix, adapt, build upon this work non-commercially, and license their derivative works on different terms, provided the original work is properly cited and the use is non-commercial. See: http://creativecommons.org/ licenses/by-nc/4.0/

Correspondence to: Shuhei Komatsu, MD, PhD, Division of Digestive Surgery, Department of Surgery, Kyoto Prefectural University of Medicine, 465 Kajii-cho, Kawaramachihirokoji, Kamigyo-ku, Kyoto 602-8566,
Japan. skomatsu@koto.kpu-m.ac.jp

Telephone: +81-75-2515527

Fax: $+81-75-2515522$

Received: March 29, 2015

Peer-review started: March 31, 2015

First decision: June 19, 2015

Revised: July 1, 2015

Accepted: August 31, 2015

Article in press: August 31, 2015

Published online: October 14, 2015

\section{Abstract}

AIM: To assess the clinical features of hepatoduodenal lymph node (HDLN) metastasis and to clarify the optimal indication of HDLN dissection.

METHODS: We investigated a total of 276 patients who underwent gastrectomy with extended lymphadenectomy, including HDLN dissection, for gastric cancer between 1999 and 2012. Of these, 26 patients $(9.4 \%)$ had HDLN metastasis. First, we investigated the clinicopathological characteristics, their perioperative clinical outcomes, such as postoperative complications, and prognostic outcomes between patients with and without HDLN metastasis. Second, we detected the prognostic factors, particularly in patients with HDLN metastasis. Third, we assessed the therapeutic value of HDLN dissection to determine its optimal indication.

RESULTS: The five-year overall survival rate of the patients with HDLN metastasis was $29 \%$. Univariate and multivariate logistic regression analyses revealed that the tumour location (the middle or lower stomach $[P=0.005, \mathrm{OR}=5.88$ (95\%CI: 1.61-38.1) $]$ and $\mathrm{pT}$ category [T3 or T4, $P=0.017, \mathrm{OR}=4.45(95 \% \mathrm{CI}$ : 1.28-21.3)] were independent risk factors for HDLN 
metastasis. Cox proportional hazard analysis identified pN3 as an independent poor prognostic factor in the patients with HDLN metastasis $[P=0.021, \mathrm{HR}=$ 5.17 (95\%CI: 1.8-292)]. For patients who underwent radical HDLN dissection, HDLN metastasis was a prognostic indicator in pN3 gastric cancer $(P<0.0001)$, but not pN1-2 $(P=0.602)$. Furthermore, the index of therapeutic value of HDLN dissection for gastric cancer in the middle or lower stomach and the upper stomach was 3.4 and 0.0 , respectively.

CONCLUSION: We suggest that HDLN dissection should be indicated for pN1 or pN2 gastric cancers located at the middle or lower stomach.

Key words: Gastric cancer; Hepatoduodenal lymph node; D2 lymphadenectomy; Prognostic factor; Tumor location

() The Author(s) 2015. Published by Baishideng Publishing Group Inc. All rights reserved.

Core tip: Gastric cancer located at the middle or lower stomach is a risk factor of hepatoduodenal lymph node (HDLN) metastasis and indicates relatively high therapeutic value of HDLN dissection. N-category, in especially pN3, is an independent poor prognostic factor in gastric cancer patients with HDLN metastasis. HDLN dissection should be indicated for N1 or N2 gastric cancers located at the middle or lower stomach.

Imamura T, Komatsu S, Ichikawa D, Kosuga T, Okamoto K, Konishi H, Shiozaki A, Fujiwara H, Otsuji E. Clinical characteristics of hepatoduodenal lymph node metastasis in gastric cancer. World J Gastroenterol 2015; 21(38): 10866-10873 Available from: URL: http://www.wjgnet.com/1007-9327/full/ v21/i38/10866.htm DOI: http://dx.doi.org/10.3748/wjg.v21. i38.10866

\section{INTRODUCTION}

Gastric cancer is one of the most common causes of death from cancer worldwide ${ }^{[1]}$. Recent advances in diagnostic techniques, less invasive treatment techniques, and perioperative management have increased the early detection of gastric cancer and decreased the mortality and morbidity ${ }^{[1,2]}$. Patients with advanced stage disease, however, still present a poor prognostic outcome and have a high incidence of lymph node metastasis. Therefore, nodal status is the strongest predictor of the prognosis of gastric cancer patients, and treatment strategy against metastatic lymph nodes is the most important clinical issue ${ }^{[3-10]}$.

Although radical gastrectomy with lymphadenectomy is recognized as the best strategy for macroscopic tumour clearance for advanced gastric cancer, criteria for optimal lymphadenectomy are different between Eastern and Western countries, because of differences in the number of obese patients, for whom a surgical approach is difficult, and differences in the epidemiologic characteristics of gastric cancer ${ }^{[11,12]}$. For example, D1 lymphadenectomy, which is a dissection of the perigastric lymph nodes, is mainly performed for advanced gastric cancer in Western countries, whereas D2 lymphadenectomy, which is a dissection of the nodes along the celiac artery and its branches in addition to the perigastric lymph nodes, is routinely performed for advanced gastric cancer in Eastern countries ${ }^{[12]}$.

Recently, a 15-year Dutch trial demonstrated fewer locoregional recurrences of gastric cancer and better long-term survival benefit in patients with D2 lymphadenectomy compared with those with D1 lymphadenectomy ${ }^{[13]}$. Therefore, the therapeutic value of D2 lymphadenectomy has started to be reevaluated in Western countries ${ }^{[14,15]}$. In this study, we focused on the hepatoduodenal lymph node (HDLN), especially the lymph node at station No. 12a. This node is defined as a hepatoduodenal ligament lymph node along the proper hepatic artery ${ }^{[16]}$, and the Japanese treatment guidelines ${ }^{[17]}$ recommend it to be routinely removed as a standard procedure for D2 lymphadenectomy. On the other hand, the HDLN is not removed in Western countries, and HDLN metastasis is classified as distant metastasis according to the $7^{\text {th }}$ American Joint Committee on Cancer (AJCC) staging manual ${ }^{[18]}$, although a recent report indicates the inappropriateness of including the HDLN in the distant metastatic lymph node group in all gastric cancers ${ }^{[19]}$.

In this study, we hypothesized that HDLN metastasis could be an indicator of poor prognosis in some subgroups of gastric cancer and that it could also be a governor of local metastatic control in other subgroups. We aimed to verify these hypotheses and to clarify the optimal indication of HDLN dissection retrospectively from patients' hospital records.

\section{MATERIALS AND METHODS}

\section{Study population of gastric cancer patients}

A total of 276 consecutive patients that underwent gastrectomy with HDLN dissection, with curative intention, for gastric cancer in the Division of Digestive Surgery, Department of Surgery, Kyoto Prefectural University of Medicine, between January 1999 and December 2012 were retrospectively analysed from their hospital records. Surgical procedures comprised a distal gastrectomy in 211 patients, a total gastrectomy in 59 patients, a pancreaticoduodenectomy in 5 patients, and a proximal gastrectomy in 1 patient according to the preoperative stage and tumour location. Resected specimens were examined and evaluated by pathologists based on classifications of the $14^{\text {th }} J_{\text {CGC }}{ }^{[16]}$ and the AJCC staging manual ${ }^{[18]}$. As a result, 90 patients were staged as pT1, 37 as pT2, 64 as pT3, and 85 as pT4. Histological types were classified as differentiated (papillary adenocarcinoma, 
Imamura T et al. Hepatoduodenal lymph node metastasis in gastric cancer

Table 1 Comparison of the clinicopathological features between patients with and without hepatoduodenal lymph node metastasis $n$ (\%)

\begin{tabular}{|c|c|c|c|c|c|c|}
\hline & \multirow[t]{2}{*}{$n$} & \multicolumn{2}{|c|}{ HDLN metastasis } & \multirow{2}{*}{$\begin{array}{c}\text { Univariate } \\
P \text { value }\end{array}$} & \multicolumn{2}{|c|}{ Multivariate } \\
\hline & & Positive & Negative & & OR $(95 \% \mathrm{Cl})$ & $P$ value \\
\hline Total & 276 & 26 & 250 & & & \\
\hline \multicolumn{7}{|l|}{ Sex } \\
\hline Male & 186 & $16(62)$ & $170(68)$ & & & \\
\hline Female & 90 & $10(38)$ & $80(32)$ & 0.509 & - & \\
\hline \multicolumn{7}{|l|}{ Age (yr) } \\
\hline$<65$ & 134 & $10(38)$ & $124(50)$ & & & \\
\hline$\geqslant 65$ & 142 & $16(62)$ & $126(50)$ & 0.277 & - & \\
\hline \multicolumn{7}{|l|}{ Tumor location } \\
\hline $\mathrm{U}$ & 64 & $2(8)$ & $62(25)$ & & & \\
\hline $\mathrm{M}$ and $\mathrm{L}$ & 212 & $24(92)$ & $188(75)$ & 0.029 & $5.88(1.61-38.1)$ & 0.005 \\
\hline \multicolumn{7}{|l|}{ CA 19-9 (U/mL) } \\
\hline$<10$ & 132 & $9(35)$ & $123(49)$ & & & \\
\hline$\geqslant 10$ & 144 & $17(65)$ & $127(51)$ & 0.153 & - & \\
\hline \multicolumn{7}{|l|}{ CEA (ng/mL) } \\
\hline$<3$ & 195 & $16(62)$ & $179(72)$ & & & \\
\hline$\geqslant 3$ & 81 & $10(38)$ & $71(28)$ & 0.295 & - & \\
\hline \multicolumn{7}{|c|}{ Histopathological type } \\
\hline Differentiated & 135 & $10(38)$ & $125(50)$ & & & \\
\hline Undifferentiated & 141 & $16(62)$ & $125(50)$ & 0.260 & - & \\
\hline \multicolumn{7}{|l|}{ Venous invasion } \\
\hline$(-)$ & 173 & $12(46)$ & $161(64)$ & & & \\
\hline$(+)$ & 103 & $14(54)$ & $89(36)$ & 0.072 & - & \\
\hline \multicolumn{7}{|l|}{ Lymphatic invasion } \\
\hline$(-)$ & 105 & $3(12)$ & $102(42)$ & & & \\
\hline$(+)$ & 171 & $23(88)$ & $148(58)$ & 0.002 & - & \\
\hline \multicolumn{7}{|l|}{ Tumor size (mm) } \\
\hline$<45$ & 119 & $5(19)$ & $114(46)$ & & & \\
\hline$\geqslant 45$ & 157 & $21(81)$ & $136(54)$ & 0.007 & - & \\
\hline \multicolumn{7}{|l|}{$\mathrm{T}$ category } \\
\hline $\mathrm{T} 1$ and $\mathrm{T} 2$ & 127 & $3(12)$ & $124(50)$ & & & \\
\hline $\mathrm{T} 3$ and $\mathrm{T} 4$ & 149 & $23(88)$ & $126(50)$ & $<0.0001$ & $4.45(1.28-21.3)$ & 0.017 \\
\hline
\end{tabular}

HDLN: Hepatoduodenal lymph node; CEA: Carcinoembryonic antigen; CA 19-9: Carbohydrate antigen 19-9; U: Upper gastric body; M: Middle gastric body; L: Lower gastric body.

or moderately or well-differentiated adenocarcinoma) or undifferentiated (poorly differentiated or undifferentiated adenocarcinoma, signet-ring cell carcinoma, or mucinous adenocarcinoma) based on the $14^{\text {th }}$ JCGC $^{[16]}$.

Of all 276 patients, 182 patients (66\%) received adjuvant chemotherapy, but 94 patients (34\%) did not. S-1 or 5-fluorouracil was administered as a key drug of adjuvant chemotherapy. None of the patients received adjuvant radiotherapy or chemoradiotherapy. All patients were examined in the outpatient clinic, where abdominal ultrasound, computed tomography (CT), and measurement of levels of carcinoembryonic antigen (CEA) and carbohydrate antigen 19-9 (CA19-9) were performed every 3-6 mo after surgery. All patients gave their informed consent in writing.

\section{Analysis of surgical outcomes and clinicopathological factors}

To reconfirm the feasibility and safety of HDLN dissection, we first investigated the clinicopathological characteristics of all patients who underwent HDLN dissection (Table 1) and their perioperative clinical outcomes, such as postoperative complications (Table 2). Second, to evaluate the prognostic differences, survival rates after surgery were compared between patients with and without HDLN metastasis (Figure 1). Risk factors for HDLN metastasis were also investigated (Table 1). Moreover, we detected the prognostic factors, particularly in patients with HDLN metastasis (Table 3 and Figure 2). Third, we assessed the therapeutic value of HDLN dissection to determine its optimal indication (Table 4). The incidence of each lymph node metastasis was calculated by dividing the number of patients with pathological lymph node metastasis by the number of the patients with the lymph node dissection. The index of therapeutic value of lymphadenectomy was calculated by multiplying the incidence of each lymph node metastasis by the fiveyear survival rate of the patients with metastasis at each nodal station and then dividing by $100^{[20]}$.

\section{Statistical analysis}

All continuous variables were classified into two groups based on the median value of each parameter. The $\chi^{2}$ test and Fisher's exact test were used to compare clinicopathological characteristics between patients with and without HDLN metastasis. Multivariate stepwise logistic regression analysis was performed to identify the independent risk factors associated with HDLN 
Table 2 Complications after gastrectomy with extended lymphadenectomy

\begin{tabular}{lr}
\hline Complications & $\boldsymbol{n}(\%)$ \\
\hline Anastomotic leakage & $12(4.3)$ \\
Pancreatic fistula & $8(2.9)$ \\
Intra-abdominal abscess & $4(1.4)$ \\
Surgical site infection & $26(9.4)$ \\
Pneumonia & $4(1.4)$ \\
Cholecystitis & $3(1.1)$ \\
Pancreatitis & $6(2.2)$ \\
Hepatic dysfunction & $2(0.7)$ \\
Stenosis at anastomotic site & $10(3.6)$ \\
Ileus & $11(4.0)$ \\
Post-operative hemorrhage & $2(0.7)$ \\
\hline
\end{tabular}

metastasis. Survival curves were estimated using the Kaplan-Meier method, and statistical differences were examined using the log-rank test. Univariate and multivariate survival analyses were performed using the likelihood ratio test of the stratified Cox proportional hazards model. $P<0.05$ was considered statistically significant.

\section{RESULTS}

\section{Clinicopathological characteristics and perioperative clinical outcomes in patients who underwent HDLN dissection}

We investigated clinicopathological characteristics in the patients who underwent gastrectomy with D2 lymphadenectomy, including HDLN dissection, based on Japanese guidelines (Table 1 ). Tumours in the middle or lower stomach $(P=0.029)$, tumour size of $45 \mathrm{~mm}$ and more $(P=0.007)$, the presence of lymphatic invasion $(P=0.002)$, and T category of T3 or T4 $(P<0.0001)$ were more frequently observed in the patients with HDLN metastasis. Multivariate stepwise logistic regression analysis identified tumours in the middle or lower stomach $(P=0.005, \mathrm{OR}=5.88)$ and $\mathrm{T}$ category of T3 or T4 $(P=0.017, \mathrm{OR}=4.45)$ as independent risk factors of HDLN metastasis. We also analysed complications that were observed after D2 gastrectomy, including HDLN lymphadenectomy, which were defined by the Clavien-Dindo classification as type II or more ${ }^{[21]}$ (Table 2). The incidence of anastomotic leakage, pancreatic fistula, and intraabdominal abscess was $4.3 \%, 2.9 \%$, and $1.4 \%$, respectively, and these were not as high as those in previous reports ${ }^{[11,22]}$. One patient $(0.3 \%)$ died as a result of surgery.

\section{Long-term prognosis of patients with or without HDLN metastasis}

Next, we analysed the long-term prognosis of the patients. The five-year overall survival (OS) rate of those with or without HDLN metastasis was $29 \%$ or $72 \%$, respectively $(P<0.0001)$ (Figure $1 \mathrm{~A})$. Limited to node-positive patients, the five-year OS rate of

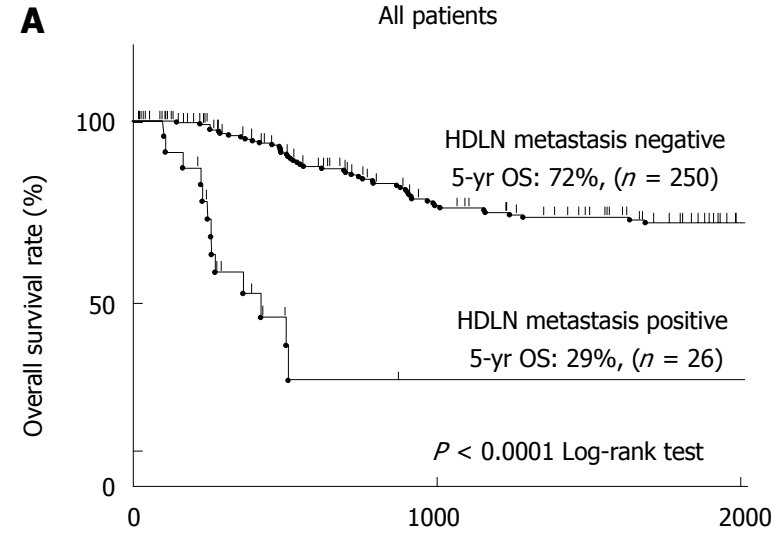

Time after survival (d)

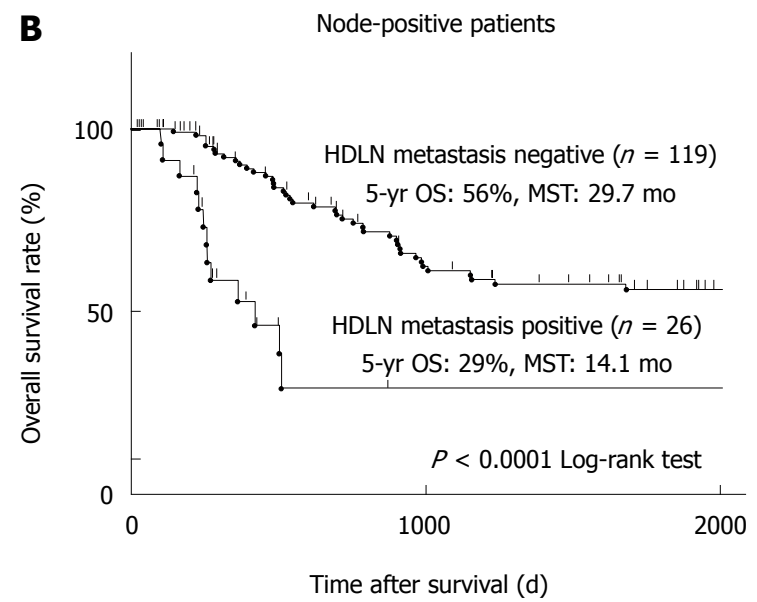

Figure 1 Five-year overall survival of gastric cancer patients based on hepatoduodenal lymph node metastasis. A: All 276 patients analysed in this study were divided into two groups based on hepatoduodenal lymph node (HDLN) metastasis. A group with HDLN metastasis $(n=26)$ and that without HDLN metastasis $(n=250)$ were compared. Kaplan-Meier survival curves were statistically analysed by the log-rank test $(P<0.0001)$; B: The patients who had lymph node metastasis $(n=145)$ were divided into two groups and analysed as described in panel a (26 patients with HDLN metastasis and 119 patients without HDLN metastasis, $P<0.0001)$.

those with or without HDLN metastasis was $29 \%$ or $56 \%$, respectively $(P<0.0001)$ (Figure $1 \mathrm{~B})$. Median survival time (MST) of the node-positive patients with or without HDLN metastasis was $14.1 \mathrm{mo}$ or $29.7 \mathrm{mo}$, respectively (Figure $1 \mathrm{~B}$ ).

\section{Prognostic factors of patients with HDLN metastasis} and correlation between the prognosis and nodal status We next investigated the prognostic factors of patients with HDLN metastasis. Univariate analysis revealed that pN3 patients, whose total number of metastatic lymph nodes is seven or more, showed significantly poorer prognosis than pN1 or pN2 patients $(P=$ 0.002 , the five-year survival rate of pN3 or pN1-2 was $0 \%$ or $62.5 \%$, respectively) (Table 3 and Figure $2 \mathrm{~A}$ ). Multivariate analysis using the Cox proportional hazard model showed that pN3 was an independent poor prognostic factor in patients with HDLN metastasis 
Imamura T et al. Hepatoduodenal lymph node metastasis in gastric cancer

Table 3 Univariate and multivariate analyses of the prognostic factors in patients with hepatoduodenal lymph node metastasis

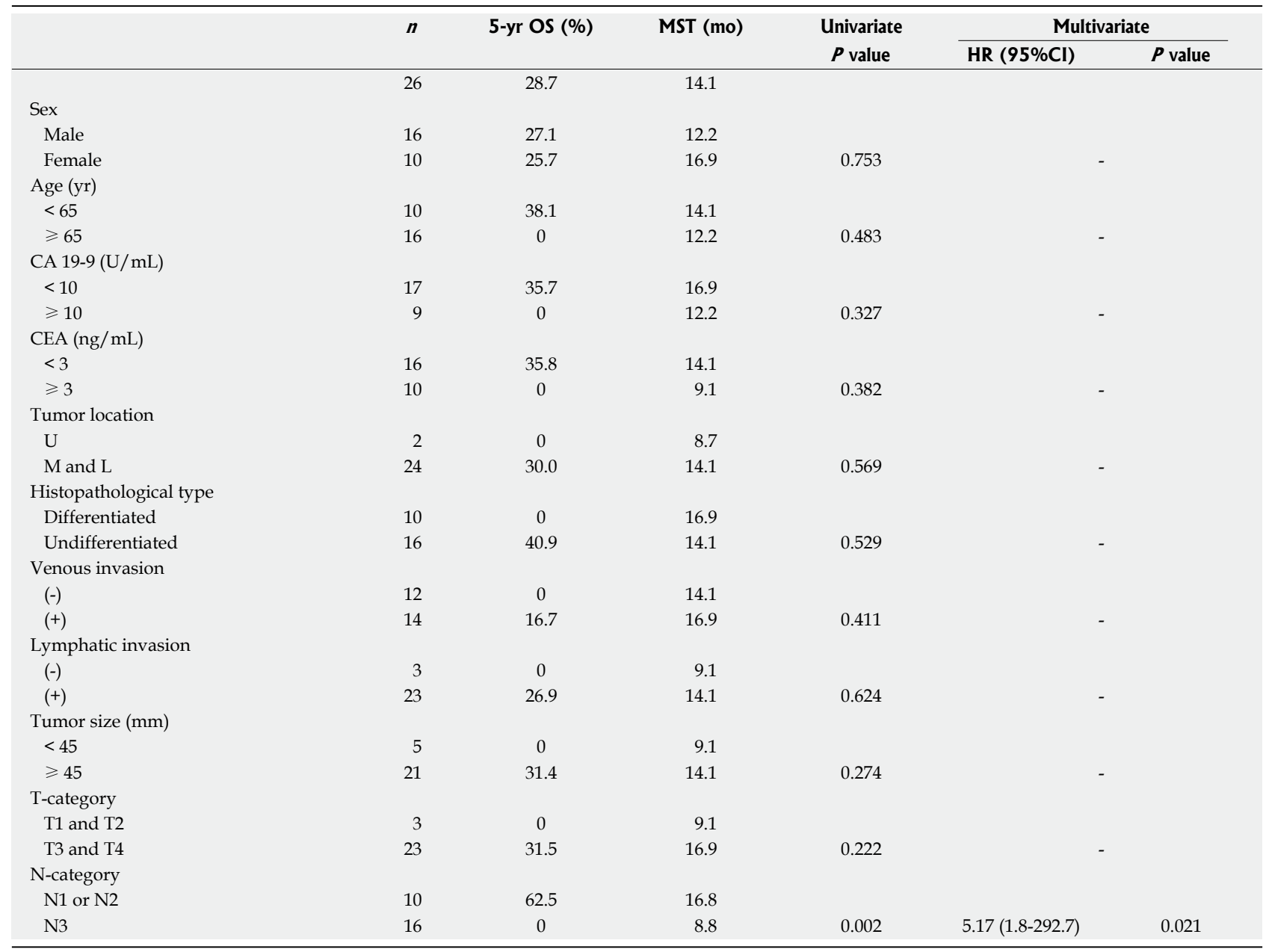

OS: Overall survival; MST: Median survival time; CEA: Carcinoembryonic antigen; CA 19-9: Carbohydrate antigen 19-9; U: Upper gastric body; M: Middle gastric body; L: Lower gastric body.

$(P=0.021, \mathrm{HR}=5.17)$ (Table 3$)$. Limited to $\mathrm{pN1}$ and $\mathrm{pN} 2$ patients analysed, there was no significant prognostic difference between the patients with and without HDLN metastasis $(P=0.602)$ (Figure $2 \mathrm{~B}$ ). On the other hand, in pN3 patients, the five-year survival rate of those with or without HDLN metastasis was $0 \%$ or $32.2 \%$, and the median survival time (MST) of those with or without HDLN metastasis was 8.8 mo or 30.2 mo (Figure $2 \mathrm{C}$ ), suggesting that the prognosis of those patients with HDLN metastasis was significantly poorer than that of those without HDLN metastasis ( $P$ $<0.001)$.

\section{Therapeutic value index and therapeutic benefit of HDLN dissection}

Lastly, we assessed the index of therapeutic value of lymphadenectomy ${ }^{[20]}$ at each nodal station in all patients who underwent D2 gastrectomy (Table 4). The therapeutic value of lymphadenectomy of HDLN was 2.7 , which was relatively low in comparison with those of the perigastric nodes at stations No. 1 to No. 7 , which were in the range of 2.7 to 18.2 . However, the index of HDLN (No. 12a) for tumours in the middle or lower stomach was 3.4, which was relatively higher than that for tumours in the upper stomach, which was 0.0 , suggesting that HDLN dissection could provide some advantages to patients with gastric cancer in the middle or lower stomach.

\section{DISCUSSION}

It is still unclear whether HDLN metastasis is a poor prognostic indicator or a determining factor of local metastasis such that its removal by surgery provides survival benefit. Moreover, the indication of HDLN dissection is controversial between Eastern and Western countries. In this study, we hypothesized that there are some far advanced patient subgroups for whom HDLN metastasis could be a poor prognostic indicator, and that there are other subgroups for whom dissection of HDLN with metastasis could provide an advantage. To verify these hypotheses, the clinicopathological factors and survival rates of patients who underwent HDLN dissection were analysed 

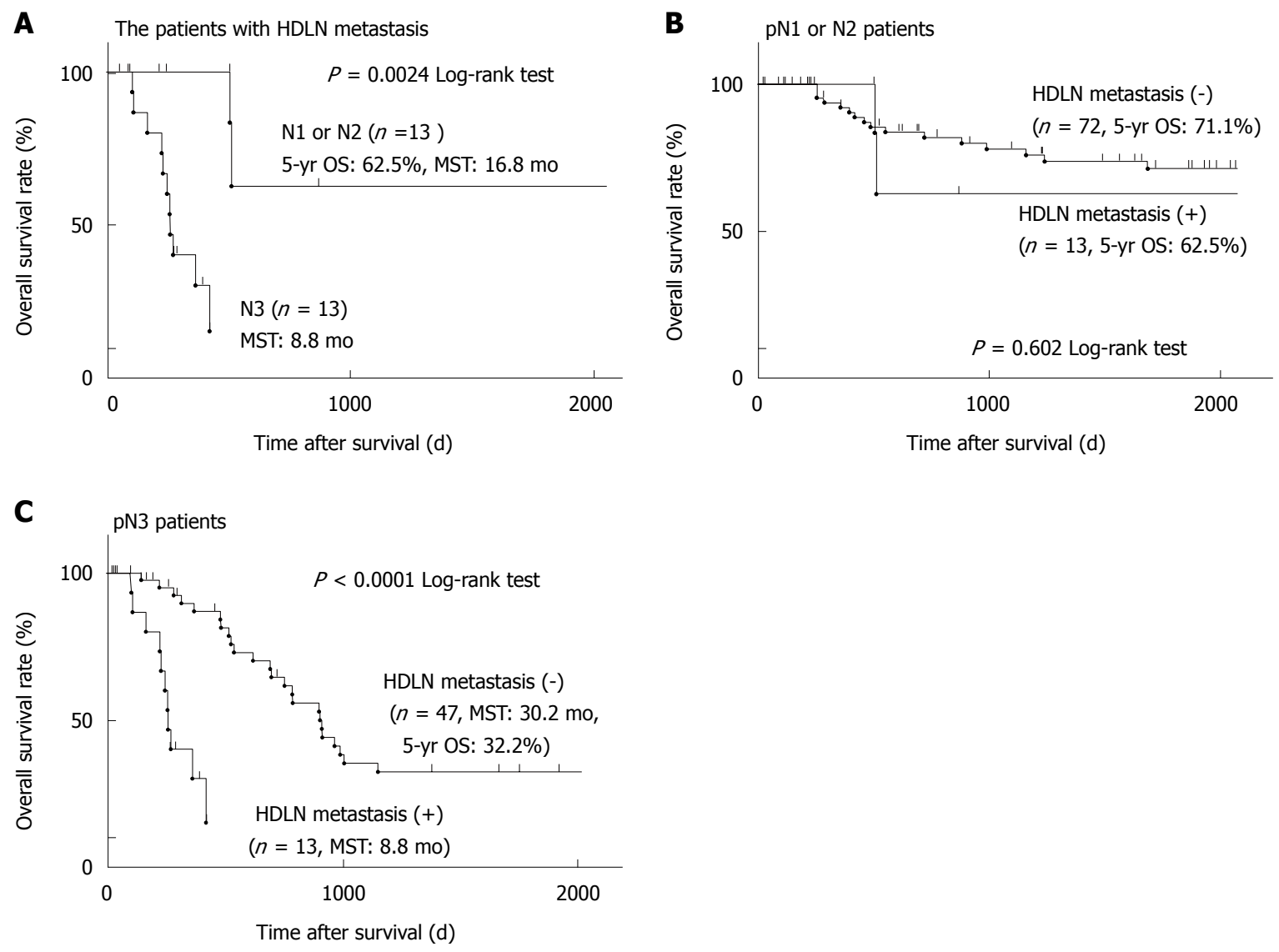

Figure 2 Five-year overall survival curves of gastric cancer patients based on the extent of lymph node metastasis. A: Twenty-six patients who had hepatoduodenal lymph node (HDLN) metastasis were divided into two groups based on the extent of lymph node metastasis. A group of pathological ( $p$ )N1 or N2 $(n=10)$ and that of pN3 $(n=16)$ were compared as described in Figure $1(P=0.0024) ; \mathrm{B}$ : All 82 pN1 or N2 patients were divided into two groups based on HDLN metastasis and analysed as described in Figure 1 (10 patients with HDLN metastasis and 72 patients without HDLN metastasis, $P=0.602$ ); C: All 63 pN3 patients were analysed as described in Figure 1 ( 16 patients with HDLN metastasis and 47 patients without HDLN metastasis, $P<0.0001$ ).

retrospectively. Consequently, HDLN metastasis was clearly identified as a poor prognostic indicator in patients with a tumour in the upper stomach or with pN3 gastric cancer, as well as a key factor controlling local recurrence in patients with pN1and pN2 gastric cancer.

According to the JCGC and the treatment guideline ${ }^{[16,17]}$, the classification of regional lymph nodes and the indication of lymphadenectomy were defined by the extent of gastrectomy, regardless of tumour location. Currently, HDLN is included in the lymph nodes which are routinely removed in advanced gastric cancer patients, even when a tumour is located in the upper stomach. However, our study revealed that patients with a tumour in the upper stomach as well as HDLN metastasis had extremely poor prognosis, and that the index of therapeutic value of HDLN dissection for those patients was 0.0, suggesting it provided no advantages, which is consistent with the previous report ${ }^{[20]}$. Thus, HDLN dissection for tumours in the upper stomach should not be recommended as a standard procedure of D2 lymphadenectomy. As described above, because the $7^{\text {th }}$ AJCC staging manual $^{[18]}$ defines HDLN metastasis as distant metastasis, HDLN is not removed in Western countries.
Our study, however, demonstrated that HDLN dissection provided a relatively high survival rate to the patients who had pN1 or pN2 gastric cancer in the middle or lower stomach, regardless of the presence of HDLN metastasis (Figure 2 and Table 3). Therefore, the tumour location is an important factor in making a preoperative decision about whether HDLN dissection should be performed.

There is no doubt that differences in treatment indications for gastric cancer between Eastern and Western countries are greatly influenced by the features of cancer biology, epidemiology, and surgical difficulties in those countries ${ }^{[11,22-24]}$. Concerning tumour location, the incidence of upper gastric cancer in the United States (51\%) was higher than that in Japan $(17 \%)^{[22]}$. This might greatly influence the treatment indication of lymphadenectomy in each country. Recently, however, the incidence of upper gastric cancer is increasing in Eastern countries, as shown in this study [23\% (64/276)] (Table 1 ). Using the multivariate logistic regression analysis (Table 1 ) and the index of therapeutic values (Table 4), we revealed that the tumour location is an important factor in making a decision about HDLN dissection. Based on this, therefore, we suggest that the guidelines 
Table 4 Index of estimated benefit from hepatoduodenal lymph node dissection

\begin{tabular}{|c|c|c|c|c|}
\hline Nodal station & & $\begin{array}{l}\text { Incidence of } \\
\text { LNM (\%) }\end{array}$ & $\begin{array}{l}\text { 5-yr OS of patients } \\
\text { with LNM (\%) }\end{array}$ & Index \\
\hline No. 1 & & 41.0 & 43.9 & 18.0 \\
\hline No. 2 & & 16.2 & 45.8 & 7.4 \\
\hline No. 3 & & 32.2 & 56.4 & 18.2 \\
\hline No. $4 \mathrm{sa}$ & & 8.1 & 75.0 & 6.1 \\
\hline No. $4 \mathrm{sb}$ & & 6.6 & 40.6 & 2.7 \\
\hline No. $4 \mathrm{~d}$ & & 22.9 & 59.8 & 13.7 \\
\hline No. 5 & & 12.5 & 53.2 & 6.7 \\
\hline No. 6 & & 19.2 & 60.6 & 11.6 \\
\hline No. 7 & & 12.8 & 47.5 & 6.1 \\
\hline No. $8 \mathrm{a}$ & & 13.3 & 55.9 & 7.4 \\
\hline No. 9 & & 19.7 & 32.1 & 6.3 \\
\hline No. 10 & & 1.2 & 100.0 & 1.2 \\
\hline No. $11 \mathrm{p}$ & & 23.7 & 56.5 & 13.4 \\
\hline No. 11d & & 0.0 & NA & NA \\
\hline \multirow[t]{2}{*}{ No. 12a (HDLN) } & & 9.4 & 28.7 & 2.7 \\
\hline & Tumor loc & ation & & \\
\hline No. 12a (HDLN) & $\mathrm{U}$ & 3.1 & 0.0 & 0.0 \\
\hline No. 12a (HDLN) & $\mathrm{M}$ and $\mathrm{L}$ & 11.3 & 30.0 & 3.4 \\
\hline
\end{tabular}

The index of therapeutic value of lymph node dissection was calculated by multiplying the incidence of metastasis by the 5-year survival rate of patients with metastasis at each nodal station and then dividing by $100^{12}$. OS: Overall survival; LNM: Lymph node metastasis; HDLN: Hepatoduodenal lymph node; U: Upper gastric body; M: Middle gastric body; L: Lower gastric body; NA: Not applicable.

should include this factor and should be standardized worldwide.

Our results indicate that HDLN dissection could salvage HDLN metastasis in patients with pN2 or lesser lymph node metastasis, because there was no significant prognostic difference between the patients with and without HDLN metastasis ( $P=$ 0.602 ) after radical HDLN dissection. Other studies, however, reported the potential survival benefit of lymphadenectomy, such as prophylactic para-aortic lymph node (PAN) dissection, for curable gastric cancer in a limited number of patients ${ }^{[25,26]}$, whereas it was not demonstrated in a randomized clinical trial (RCT) (JCOG9501) ${ }^{[27]}$. Moreover, prospective RCTs, such as JCOG0001 and JCOG0405 ${ }^{[28,29]}$, demonstrated the survival benefit of neoadjuvant chemotherapy followed by extended surgery with PAN dissection for gastric cancer patients with only PAN or bulky N2 metastasis (limited putative pN3 metastasis). Similarly to these studies, we speculate that the survival benefit may also be obtained in pN3 patients by neoadjuvant chemotherapy followed by extended surgery with HDLN dissection. For this issue, further prospective studies are warranted.

Our results indicate the significance in making a decision about HDLN dissection depending on the tumour location and pathological N-category. However, there is a major problem in diagnosing metastatic lymph nodes accurately before surgery using current imaging methods. We previously generated a simple math formula to estimate preoperative metastatic nodal counts using multidetector row computed tomography
(MDCT); Pathologic counts $=1.63 \times$ (counts by MDCT) $+2.5^{[30]}$. Based on this formula, 3 or more nodal counts by MDCT might be considered pN3. Therefore, for patients with less than 3 putative metastatic nodal counts by MDCT, who are considered pN1 or pN2, D2 lymphadenectomy with HDLN dissection should be performed. On the other hand, for patients with 3 or more nodal counts by MDCT, neoadjuvant chemotherapy may be considered as a treatment choice before surgical resection with extended lymphadenectomy, including HDLN dissection.

Our study, however, have some limitations. The population of the cohort was relatively small. A prospective study may be needed to validate the indication of HDLN dissection. Therefore, although the therapeutic value of HDLN dissection for gastric cancer is currently limited, we would suggest that HDLN dissection can provide a prognostic benefit to pN1 and pN2 gastric cancer patients whose tumour is located in the middle or lower stomach.

\section{COMMENTS}

\section{Background}

It is still unclear whether hepatoduodenal lymph node (HDLN) metastasis is a poor prognostic indicator or a determining factor of local metastasis such that its removal by surgery provides survival benefit. Moreover, the indication of HDLN dissection is controversial between Eastern and Western countries.

\section{Research frontiers}

This study was designed to evaluate the clinical characteristics and impact of HDLN metastasis on the clinical course and to clarify the optimal indication of HDLN dissection.

\section{Innovations and breakthroughs}

HDLN metastasis was clearly identified as a poor prognostic indicator in patients with a tumour in the upper stomach or with pN3 gastric cancer, as well as a key factor controlling local recurrence in patients with pN1and pN2 gastric cancer.

\section{Applications}

The results indicate the significance in making a decision about HDLN dissection depending on the tumour location and pathological N-category. For patients with lesions considered as pN1 or pN2, D2 lymphadenectomy with HDLN dissection should be performed.

\section{Terminology}

Hepatoduodenal lymph node is defined as a hepatoduodenal ligament lymph node along the proper hepatic artery, and the Japanese treatment guidelines recommend it to be routinely removed as a standard procedure for D2 lymphadenectomy. On the other hand, the HDLN is not removed in Western countries, and HDLN metastasis is classified as distant metastasis according to the $7^{\text {th }}$ American Joint Committee on Cancer staging manual.

\section{Peer-review}

The study is of high level, the results shown in this work could be a contribution for that the medical teams take a good decision that can help a better survival of the patient. The results could be taken in account in different hospitals in the world.

\section{REFERENCES}

1 Jemal A, Bray F, Center MM, Ferlay J, Ward E, Forman D. Global 
cancer statistics. CA Cancer J Clin 2011; 61: 69-90 [PMID: 21296855 DOI: 10.3322/caac.20107]

2 Wadhwa R, Song S, Lee JS, Yao Y, Wei Q, Ajani JA. Gastric cancer-molecular and clinical dimensions. Nat Rev Clin Oncol 2013; 10: 643-655 [PMID: 24061039 DOI: 10.1038/nrclinonc.2013.170]

3 Hartgrink HH, Jansen EP, van Grieken NC, van de Velde CJ. Gastric cancer. Lancet 2009; 374: 477-490 [PMID: 19625077 DOI: 10.1016/S0140-6736(09)60617-6]

4 Zhang J, Zhou Y, Jiang K, Shen Z, Ye Y, Wang S. Evaluation of the seventh AJCC TNM staging system for gastric cancer: a metaanalysis of cohort studies. Tumour Biol 2014; 35: 8525-8532 [PMID: 24696259 DOI: 10.1007/s13277-014-1848-6]

5 Dikken JL, Verheij M, Cats A, Jansen EP, Hartgrink HH, van de Velde CJ. Extended lymph node dissection for gastric cancer from a European perspective. Gastric Cancer 2011; 14: 396-398 [PMID: 21837457 DOI: 10.1007/s10120-011-0081-x]

6 Brar S, Law C, McLeod R, Helyer L, Swallow C, Paszat L, Seevaratnam R, Cardoso R, Dixon M, Mahar A, Lourenco LG, Yohanathan L, Bocicariu A, Bekaii-Saab T, Chau I, Church N, Coit D, Crane CH, Earle C, Mansfield P, Marcon N, Miner T, Noh SH, Porter G, Posner MC, Prachand V, Sano T, van de Velde C, Wong $\mathrm{S}$, Coburn N. Defining surgical quality in gastric cancer: a RAND/ UCLA appropriateness study. J Am Coll Surg 2013; 217: 347-357. e1 [PMID: 23664139 DOI: 10.1016/j.jamcollsurg.2013.01.067]

7 Allum WH. Optimal surgery for gastric cancer: is more always better? Recent Results Cancer Res 2012; 196: 215-227 [PMID: 23129377 DOI: $10.1007 / 978-3-642-31629-6$ 15]

8 Russell MC, Mansfield PF. Surgical approaches to gastric cancer. $J$ Surg Oncol 2013; 107: 250-258 [PMID: 22674546 DOI: 10.1002/ jso.23180]

9 Schmidt B, Yoon SS. D1 versus D2 lymphadenectomy for gastric cancer. J Surg Oncol 2013; 107: 259-264 [PMID: 22513454 DOI: $10.1002 /$ jso.23127]

10 Wong J, Jackson P. Gastric cancer surgery: an American perspective on the current options and standards. Curr Treat Options Oncol 2011; 12: 72-84 [PMID: 21274666 DOI: 10.1007/s11864-0100136-y]

11 Bonenkamp JJ, Hermans J, Sasako M, van de Velde CJ, Welvaart K, Songun I, Meyer S, Plukker JT, Van Elk P, Obertop H, Gouma DJ, van Lanschot JJ, Taat CW, de Graaf PW, von Meyenfeldt MF, Tilanus H. Extended lymph-node dissection for gastric cancer. $N$ Engl J Med 1999; 340: 908-914 [PMID: 10089184]

12 Bickenbach K, Strong VE. Comparisons of Gastric Cancer Treatments: East vs. West. J Gastric Cancer 2012; 12: 55-62 [PMID: 22792517 DOI: 10.5230/jgc.2012.12.2.55]

13 Songun I, Putter H, Kranenbarg EM, Sasako M, van de Velde CJ. Surgical treatment of gastric cancer: 15 -year follow-up results of the randomised nationwide Dutch D1D2 trial. Lancet Oncol 2010; 11: 439-449 [PMID: 20409751 DOI: 10.1016/S14702045(10)70070-X]

14 Strong VE, Yoon SS. Extended lymphadenectomy in gastric cancer is debatable. World J Surg 2013; 37: 1773-1777 [PMID: 23649527 DOI: 10.1007/s00268-013-2070-1]

15 Degiuli M, Sasako M, Ponti A. Morbidity and mortality in the Italian Gastric Cancer Study Group randomized clinical trial of D1 versus D2 resection for gastric cancer. Br J Surg 2010; 97: 643-649 [PMID: 20186890 DOI: 10.1002/bjs.6936]

16 Japanese Gastric Cancer Association. Japanese classification of gastric carcinoma: 3rd English edition. Gastric Cancer 2011; 14: 101-112 [PMID: 21573743 DOI: 10.1007/s10120-011-0041-5]

17 Japanese Gastric Cancer Association. Japanese gastric cancer treatment guidelines 2010 (ver. 3). Gastric Cancer 2011; 14: 113-123 [PMID: 21573742 DOI: 10.1007/s10120-011-0042-4]

18 Edge SB, Byrd DR, Compton CC. American Joint Committee on Cancer (AJCC) Cancer Staging Manual (7th edn). Springer: New York, 2010

19 Lee SL, Lee HH, Ko YH, Song KY, Park CH, Jeon HM, Kim SS. Relevance of hepatoduodenal ligament lymph nodes in resectional surgery for gastric cancer. $B r J$ Surg 2014; 101: 518-522 [PMID: 24615472 DOI: $10.1002 /$ bjs.9438]

20 Sasako M, McCulloch P, Kinoshita T, Maruyama K. New method to evaluate the therapeutic value of lymph node dissection for gastric cancer. Br J Surg 1995; 82: 346-351 [PMID: 7796005]

21 Dindo D, Demartines N, Clavien PA. Classification of surgical complications: a new proposal with evaluation in a cohort of 6336 patients and results of a survey. Ann Surg 2004; 240: 205-213 [PMID: 15273542]

22 Noguchi Y, Yoshikawa T, Tsuburaya A, Motohashi H, Karpeh MS, Brennan MF. Is gastric carcinoma different between Japan and the United States? Cancer 2000; 89: 2237-2246 [PMID: 11147594]

23 Shim JH, Song KY, Jeon HM, Park CH, Jacks LM, Gonen M, Shah MA, Brennan MF, Coit DG, Strong VE. Is gastric cancer different in Korea and the United States? Impact of tumor location on prognosis. Ann Surg Oncol 2014; 21: 2332-2339 [PMID: 24599411 DOI: 10.1245/s10434-014-3608-7]

24 Strong VE, Song KY, Park CH, Jacks LM, Gonen M, Shah M, Coit DG, Brennan MF. Comparison of gastric cancer survival following R0 resection in the United States and Korea using an internationally validated nomogram. Ann Surg 2010; 251: 640-646 [PMID: 20224369 DOI: 10.1097/SLA.0b013e3181d3d29b]

25 Maeta M, Yamashiro H, Saito H, Katano K, Kondo A, Tsujitani S, Ikeguchi M, Kaibara N. A prospective pilot study of extended (D3) and superextended para-aortic lymphadenectomy (D4) in patients with T3 or T4 gastric cancer managed by total gastrectomy. Surgery 1999; 125: 325-331 [PMID: 10076618]

26 Kunisaki C, Akiyama H, Nomura M, Matsuda G, Otsuka Y, Ono H, Nagahori Y, Hosoi H, Takahashi M, Kito F, Shimada H. Comparison of surgical results of D2 versus D3 gastrectomy (paraaortic lymph node dissection) for advanced gastric carcinoma: a multi-institutional study. Ann Surg Oncol 2006; 13: 659-667 [PMID: 16538414]

27 Sasako M, Sano T, Yamamoto S, Kurokawa Y, Nashimoto A, Kurita A, Hiratsuka M, Tsujinaka T, Kinoshita T, Arai K, Yamamura Y, Okajima K. D2 lymphadenectomy alone or with para-aortic nodal dissection for gastric cancer. N Engl J Med 2008; 359: 453-462 [PMID: 18669424 DOI: 10.1056/NEJMoa0707035]

28 Yoshikawa T, Sasako M, Yamamoto $S$, Sano T, Imamura H, Fujitani K, Oshita H, Ito S, Kawashima Y, Fukushima N. Phase II study of neoadjuvant chemotherapy and extended surgery for locally advanced gastric cancer. Br J Surg 2009; 96: 1015-1022 [PMID: 19644974 DOI: 10.1002/bjs.6665]

29 Tsuburaya A, Mizusawa J, Tanaka Y, Fukushima N, Nashimoto A, Sasako M. Neoadjuvant chemotherapy with S-1 and cisplatin followed by $\mathrm{D} 2$ gastrectomy with para-aortic lymph node dissection for gastric cancer with extensive lymph node metastasis. Br J Surg 2014; 101: 653-660 [PMID: 24668391 DOI: 10.1002/bjs.9484]

30 Kawaguchi T, Komatsu S, Ichikawa D, Okamoto K, Shiozaki A, Fujiwara H, Murayama Y, Kuriu Y, Ikoma H, Nakanishi M, Ochiai T, Kokuba Y, Nishimura T, Otsuji E. Nodal counts on MDCT as a surrogate marker for surgical curability in gastric cancer. Ann Surg Oncol 2012; 19: 2465-2470 [PMID: 22395992 DOI: 10.1245/ s10434-012-2283-9]

P- Reviewer: Beltran MA, Bernal G, Caboclo JLF, Hsieh CC S- Editor: Ma YJ L- Editor: A E- Editor: Liu XM 


\section{DS \\ Baishideng ${ }^{\circledR}$}

\section{Published by Baishideng Publishing Group Inc}

8226 Regency Drive, Pleasanton, CA 94588, USA

Telephone: +1-925-223-8242

Fax: +1-925-223-8243

E-mail: bpgoffice@wignet.com

Help Desk: http://www.wjgnet.com/esps/helpdesk.aspx

http://www.wjgnet.com

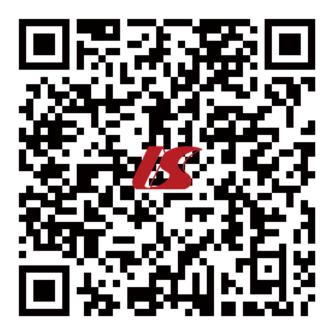

I SSN $1007-9327$ 